\title{
RISK-INFORMED SEPARATION DISTANCES FOR HYDROGEN REFUELING STATIONS
}

\author{
J. L. LaChance \\ Sandia National Laboratories, ${ }^{1}$ P.O. Box 5800, Albuquerque, NM, 87104, USA, \\ jllacha@sandia.gov
}

\begin{abstract}
The development of an infrastructure for the future hydrogen economy will require the simultaneous development of a set of codes and standards. As part of the U.S. Department of Energy Hydrogen, Fuel Cells \& Infrastructure Technologies Program, Sandia National Laboratories is developing the technical basis for assessing the safety of hydrogen-based systems for use in the development/modification of relevant codes and standards. This work includes experimentation and modeling to understand the fluid mechanics and dispersion of hydrogen for different release scenarios, including investigations of hydrogen combustion and subsequent heat transfer from hydrogen flames. The resulting technical information is incorporated into engineering models that are used for assessment of different hydrogen release scenarios and for input into quantitative risk assessments (QRA) of hydrogen facilities. The QRAs are used to identify and quantify scenarios for the unintended release of hydrogen and to identify the significant risk contributors at different types of hydrogen facilities. The results of the QRAs are one input into a risk-informed codes and standards development process that can also include other considerations by the code and standard developers. This paper describes an application of QRA methods to help establish one key code requirement: the minimum separation distances between a hydrogen refueling station and other facilities and the public at large. An example application of the risk-informed approach has been performed to illustrate its utility and to identify key parameters that can influence the resulting selection of separation distances. Important parameters that were identified include the selected consequence measures and risk criteria, facility operating parameters (e.g., pressure and volume), and the availability of mitigation features (e.g., automatic leak detection and isolation). The results also indicate the sensitivity of the results to key modeling assumptions and the component leakage rates used in the QRA models.
\end{abstract}

\subsection{SEPARATION DISTANCES}

Separation or safety distances are used to protect the public and other facilities from the consequences of potential accidents related to the operation of a facility. Separation distances are also used to reduce the potential that a minor accident at one portion of a facility propagates to another part of the facility thus increasing the resulting consequences. Specified separation distances may not provide protection against all potential accidents but they generally should address likely events initiated by a hazard located on the facility and by external hazards (e.g., earthquakes, automobiles) some of which can occur outside the boundary of the facility (e.g., a fire at an adjacent building). The latter case implies that separation distances can be two-way measures that protect adjacent structures from the hazards of the facility and also protect the facility against the hazards from adjoining facilities.

Separation distances for hydrogen facilities are provided in the International Code Councils (ICC) International Fire Code (IFC) [1] and two documents from the National Fire Protection Association (NFPA): NFPA 55 [2] and NFPA 52 [3]. Separation distances are also specified in governmental regulations such as those specfied by the Occupational Safety and Health Administration (OSHA)

\footnotetext{
${ }^{1}$ Sandia is a multi-program laboratory operated by Sandia Corporation, a Lockheed Martin Company, for the United States Department of Energy's National Nuclear Security Administration under Contract DE-AC04-94-AL85000.
} 
[4]. The separation distances currently defined in the theses codes and regulations vary according to the target that can be exposed to accident phenomenon. Typical targets include members of the public, adjacent facilities, onsite structures, other flammable or combustible material, air intake openings, and ignition sources. The separation distances can vary from one code or standard to another in addition to how they are specified. For example, both the IFC and NFPA 52 present single values, while the NFPA 55 (and OSHA) provides separation distance as a function of the total hydrogen volume. NFPA 52 also provides separation distances for the dispensing area of a refueling station. Whether the parameters currently being used to differentiate separation distances in these codes are adequate for future hydrogen refueling stations and other hydrogen facilities is an issue that is being addressed by the standards and code development organizations (SDOs). For example, higher gas storage and dispensing pressures than contemplated during the creation of the current codes are being considered for hydrogen refueling stations (gas storage cylinders with pressures of 70 $\mathrm{MPa}$ or greater are being incorporated into facility designs). A consequence of these higher pressures is that the required separation distances may be significantly greater than currently specified.

The development of separation distances for the new generation of hydrogen facilities can be determined by SDOs and evaluated by facility designers in several ways. A conservative approach is to use the worst possible accidents in terms of consequences. Such accidents may be of very low frequency such that they would likely never occur. Although this approach bounds separation distances, the resulting distances are generally prohibitive. The current separation distances do not reflect this approach. An alternative deterministic approach that is often utilized by SDOs and allowed under some regulations is to select accident scenarios that are more probable but do not provide bounding consequences. In this approach, expert opinion is generally used to select the accidents used as the basis for the prescribed separation distances. Although anecdotal experience often forms the basis for the selection of the accidents, the frequency of accidents can also be used as a selection criterion.

Figure 1 provides an example of deterministic separation distances based on one possible consequence of a hydrogen leakage event: the radiant heat flux from an ignited hydrogen jet. The figure shows the separation distances required to limit the exposure of a person to a radiant heat flux of $1.6 \mathrm{~kW} / \mathrm{m}^{2}$ which is generally accepted as a level that will not result in harm to an individual even for long exposures (this heat flux level is currently specified in the IFC [1] as a "no harm" criterion for designing hydrogen vent systems). The separation distances were calculated using a Sandia developed model for predicting the radiant heat fluxes and flammability envelopes from high pressure releases of hydrogen [5]. The calculated values are conservative since they assume free-forming jet fires that are not affected by the ground or structures and are orientated towards the target (jet fires that are orientated upwards result in separation distances that are roughly half the distance shown in Figure 1). As indicated in Figure 1, the required separation distances are significantly affected by the pressure of the hydrogen gas and the leak diameter. These insights suggests the gas storage pressure is an important parameter that should be considered when specifying separation distances and that the selection of a specified leak size and orientation is critical in determining the separation distances.

The separation distances shown in Figure 1 are generally larger than those currently specified in the ICC and NFPA codes and standards even for low pressure systems and small leak diameters. One way to reduce consequence-based separation distances is to use a higher consequence level that introduces the potential for injuring the public or damaging structures. This is illustrated in Figure 2 which shows the separation distances that would be required for different radiant heat flux levels and hydrogen gas pressures. The separation distances were evaluated for a specified leak diameter of 2.38 $\mathrm{mm}$ and only consequences related to hydrogen jets are included in this plot (the potential consequences from other possible accidents such as vapor cloud explosions were not examined in this study but must also be considered when determining separation distances). 


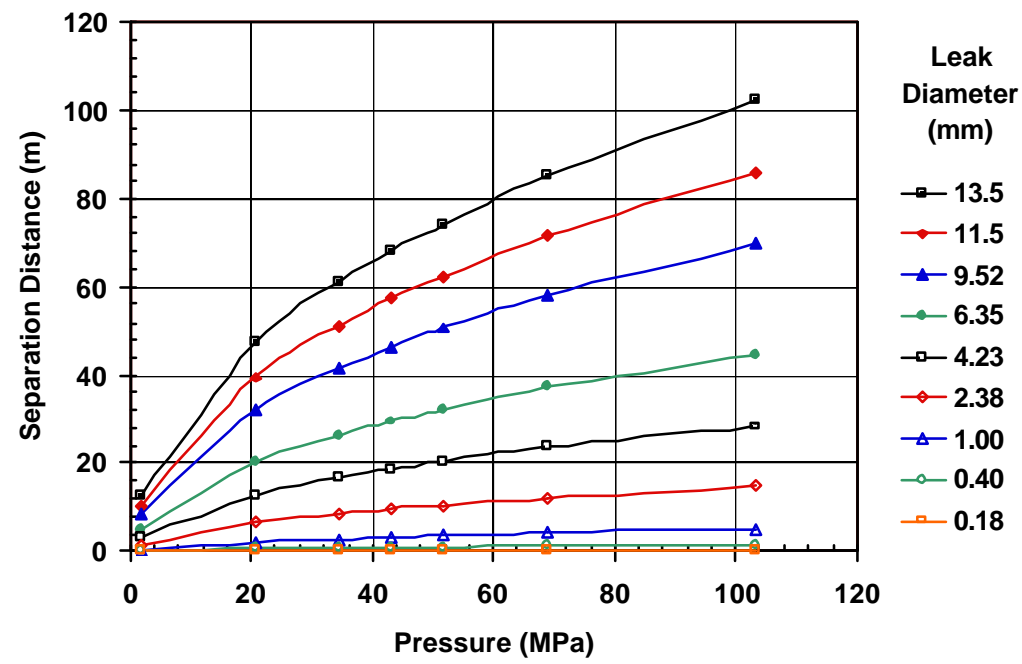

Figure 1. Separation distances required for an exposure to a radiant heat flux of $1.6 \mathrm{~kW} / \mathrm{m}^{2}$ generated by a jet

fire.

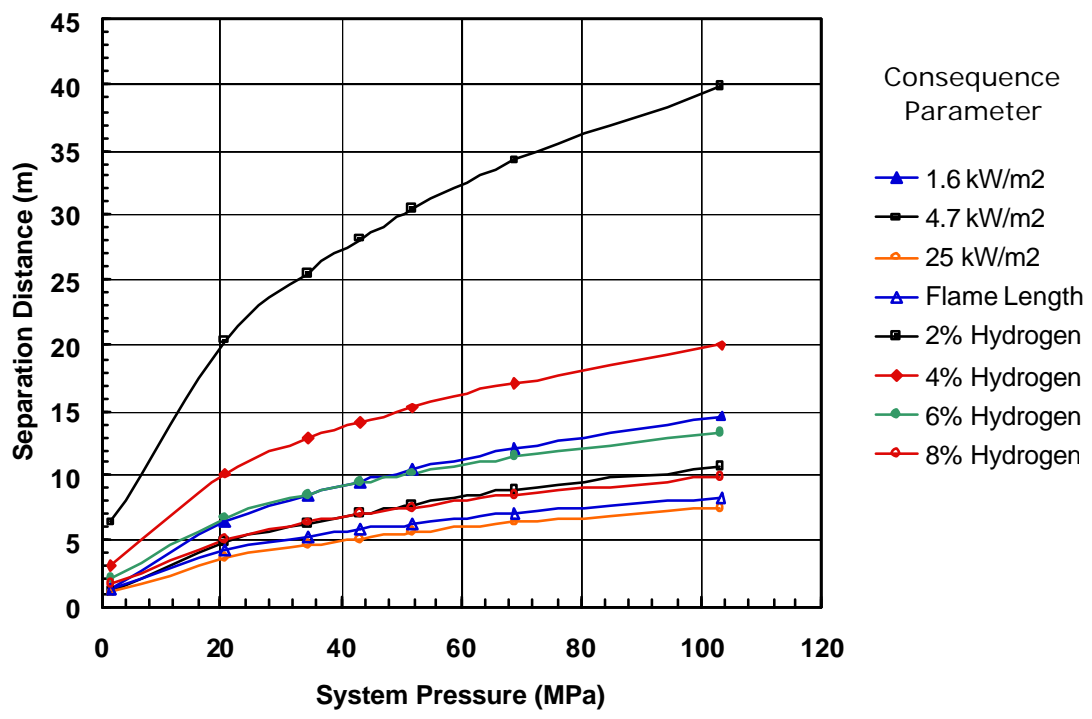

Figure 2. Separation distances required for a jet fire from a $2.38 \mathrm{~mm}$ diameter leak using different consequence parameters.

Although a variety of radiant heat flux levels and associated injury or damage levels are quoted in the literature $[6,7,8]$, the levels that were used in this study were limited to those currently listed in the IFC [1] as criteria for designing hydrogen vent systems: the $1.6 \mathrm{~kW} / \mathrm{m}^{2}$ level discussed previously, a 20 second exposure to $4.7 \mathrm{~kW} / \mathrm{m}^{2}$ which would result in second degree burns, and an extended exposure to $25 \mathrm{~kW} / \mathrm{m}^{2}$ for an extended period which would damage structures and components (short exposures to this heat flux level would also result in third degree burns that could lead to a fatality). A radiant heat flux of 4.5 to $5 \mathrm{~kW} / \mathrm{m}^{2}$ is also specified in regulations in several countries including the United States [9] and in NFPA 59A [10] as an acceptable radiation hazard level for public exposure to hydrocarbon fires. Also, it should be noted that the separation distances evaluated for a $25 \mathrm{~kW} / \mathrm{m}^{2}$ heat flux are approximately the same as those for the visible flame length of a hydrogen jet (also shown in Figure 2). Thus, the selection of this heat flux level also provides an indication of the 
separation distances that would be required for protection of personnel and structures from direct flame contact.

Figure 2 also illustrates the separation distances required for hydrogen concentrations ranging from $2 \%$ to $8 \%$. The distances corresponding to the lower flammability limit (LFL) of hydrogen (4\%) are included in this study since a delayed ignition of a hydrogen jet can injure people within the radius bounded by the LFL. The distances for a $2 \%$ hydrogen concentration (i.e., half of the LFL) are also provided since it results in a "no harm" distance that is being used in the IFC [1] as a criterion for designing hydrogen venting systems. The $6 \%$, and $8 \%$ concentration contours are provided to reflect the uncertainty in the experimental literature on the ignitable concentration of hydrogen in nonquiescent flows [5]. The hydrogen concentration in an un-ignited hydrogen jet can be used as a basis to establish the separation distance from a hydrogen storage area to the public, ignition sources, and ventilation intakes.

The separation distances shown in Figure 2 indicates that it is possible to establish reasonable consequence-based separation distances from jet fires (consideration of other types of accidents is required) even for high pressure systems if some level of personnel injury or property damage (represented in the figure by the higher radiant heat fluxes and hydrogen concentrations) is acceptable and if the evaluations are based on justifiably low leakage sizes. Anecdotal evidence of typical leak sizes or evaluation of available data is a possible method for selecting a leak size. For example, the Compressed Gas Association suggests in Reference 11 that typical leak sizes are less than $20 \%$ of the flow area of the component. However, the risk associated with these selected leak sizes should be evaluated and included in the final decision process. The risk-informed process described in the next section provides another means to determine a defensible leak size for each consequence parameter and type of accident scenario.

\subsection{RISK-INFORMED APPROACH}

An alternative approach for selecting the scenarios utilized to establish separation distances for a hydrogen facility involves the use of the estimated risk associated with the operation of the facility. The risk from the operation of a facility is the product of the frequency and consequences of all credible accidents and can be estimated using QRA. In this risk-informed approach the estimated risk for the facility is compared to an acceptable risk level to provide a basis for eliminating low risk scenarios from consideration in the determination of separation distances. A consequence of this approach is that the established separation distances will present some residual level of risk that must be acceptable by affected stake holders (i.e., the public, regulators, and facility operators). That level of risk is determined by the selected consequence measures and risk threshold used in the riskinformed evaluation. An additional benefit from the QRA analysis is that key risk drivers are identified and potential accident prevention and mitigation strategies to them can be identified and possibly specified as requirements in the codes and standards.

The proposed risk-informed approach utilizes the conceptual framework, shown in Figure 3, which was developed by the European Industrial Gases Association (EIGA) [6]. In this approach, the cumulative frequencies of different leak diameters resulting in one or more specified consequence are evaluated against the separation distances required to protect people, equipment, or structures from a specified level of harm. The accidental releases can occur due to random component failures such as pipe ruptures, overpressure events, unintentional venting, external events such as earthquakes and fires at adjoining structures, and human errors including those related to dispensing hydrogen and incorrect performance of maintenance on the facility. The availability of features to mitigate accidental releases (e.g., shutoff valves initiated by hydrogen or flame sensors) can be included in the accident frequency evaluation. A selected risk criterion is used to establish the risk-informed separation distances based on the selected consequence parameters. Hydrogen leaks resulting in risk values below this criterion could be eliminated in the separation distance evaluation. In effect, this approach can provide a basis for eliminating large leakage events which have low frequencies and 
result in significant consequences that require large separation distances to protect the public, structures, and equipment from harm.

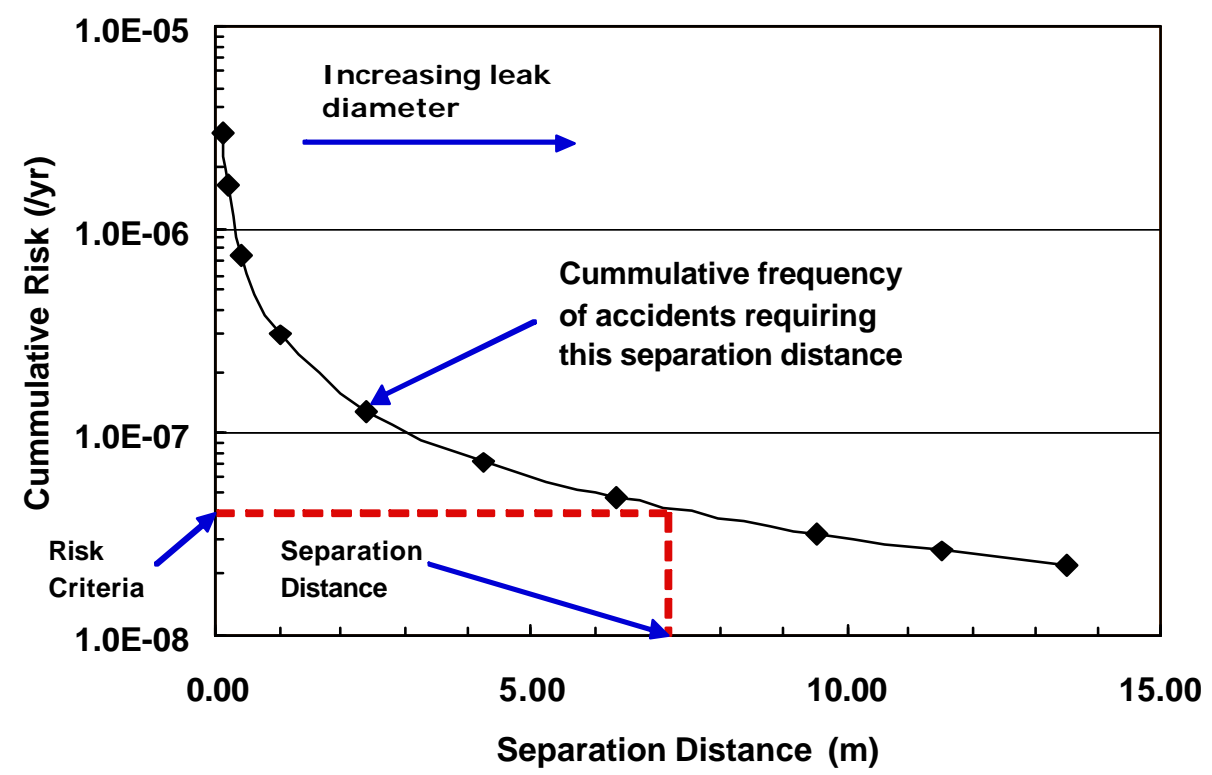

Figure 3. Risk-informed approach for establishing safety distances.

The use of a risk-informed approach requires a QRA that considers all credible hazards resulting from hydrogen-related accidents. The principle hazard associated with hydrogen facilities is uncontrolled combustion of accidentally released hydrogen gas or liquid. Possible modes of gaseous hydrogen combustion include jet fires, flash fires, deflagrations (unconfined vapor cloud explosions), and detonations. For facilities with large volumes of liquid hydrogen, additional combustion concerns include the potential for pool fires and boiling liquid expanding vapor explosions (BLEVE). Other hydrogen-related hazards such as asphyxiation and cryogenic burns are also possible but are generally of secondary importance compared to hydrogen combustion. To focus the QRA on important scenarios, deterministic evaluations can be used to show that some of these hazards physically can not occur at a specified hydrogen facility or that the separation distances required to address one hazard is bounded by another hazard.

The primary consequences from fire hazards consist of personnel injury or facility and equipment damage due to either radiant heat fluxes or direct contact with hydrogen flames. The possible consequences of explosions on humans and structures or equipment include blast wave overpressure effects, impact from fragments generated by the explosion, the collapse of buildings, and the heat effects from resulting fire balls. The current demonstration of the suggested risk-informed approach has been limited to the consideration of the radiant heat flux from a jet fire and the direct flame contact that would occur from a flash fire. The parameters examined were discussed in Section 1.

Establishment of risk criteria is another key element required to utilize a risk-informed approach. Since the primary concern is the potential for personnel injury, risk criteria can be established for all the people exposed to the consequences of facility-related accidents which could include the public located outside the boundaries of the facility, users of the facility, and the facility workers. Public risk is generally the main focus in risk assessments. In most QRA applications, the risk levels for the public are generally set one to two orders of magnitude less than the level for workers. Depending on the accident consequence, the selected risk criteria could reflect acceptance levels for either injuries or fatalities. Although the latter is generally utilized in risk assessments, the radiant heat flux criteria currently specified in regulations and standards for protecting the public are reflective of injuries such as burns (i.e., 4.5 to $5 \mathrm{~kW} / \mathrm{m}^{2}$ ) and thus may be deemed by SDOs to be the most appropriate level for 
establishing separation distances for hydrogen facilities. However, as discussed in Section 4, the use of personnel injury as a criterion for determining separation distances can introduce an unacceptable risk of fatalities.

Risk criteria can be specified with regard to individuals or the society at large. Individual risk reflects the frequency that an average person located permanently at a certain location is harmed Characterization of the population surrounding a facility is thus not required to evaluate individual risk. Societal risk reflects the relationship between the frequency and the number of people harmed. Evaluation of societal risk requires determination of the population surrounding a facility. For the application of QRA to determine the separation distances specified in codes and standards, the use of individual risk measures may be the most appropriate since they are site independent.

Selection of individual risk criteria should be based on sound arguments and reflect the consensus of all stakeholders. Ideally, the risk associated with the wide spread development of hydrogen refueling stations should not substantially increase the injury or fatality risk of an individual This concept is not new and in fact has been utilized in several industries. A critical question is what level of risk should be utilized in this concept? One option is to specify that the risk from hydrogen accidents be some fraction of the total risk to individuals from all unintentional injuries. This approach has been adopted by the Nuclear Regulatory Commission (NRC) in their efforts to risk-inform the regulations for nuclear power plants. In addition, several groups have adopted this approach for hydrogen safety applications. This includes the EIGA and the European Integrated Hydrogen Project (EIHP) [13]. The fraction of the fatality rate used by these two groups to establish a risk criterion ranges from $1 \%$ (EIHP) to $17.5 \%$ (EIGA). Recent data [12] suggest that the individual fatality risk from unintentional injuries in the United States is on the order of $3.8 \mathrm{E}-4 / \mathrm{yr}$ (the cited rate in other countries is approximately 2E-4/yr). Thus, the fatality risk criterion proposed by EIHP and EIGA are 2E-6/yr and $3.5 \mathrm{E}-5 / \mathrm{yr}$, respectively. The selection of the fractional increase in the current individual risk values that would be used in establishing hydrogen-related risk criteria is a critical decision that regulators and other policy makers will have to make if this approach is utilized.

A second option is to specify that the risk associated with hydrogen refueling stations be equal to or less than the risk associated with gasoline or compressed natural gas (CNG) stations. Unfortunately, no published risk assessments for either gasoline or CNG refueling stations that could provide those risk estimates have been identified. However, there is some limited data on the frequency of fires in public gasoline stations [14] for the five-year period of 1994-1998 (no published data for CNG stations was identified) that could be used to establish such a comparative criteria. This data indicates that the average frequency of a fire at a gasoline station is approximately $7.4 \mathrm{E}-2 / \mathrm{yr}$. A majority of the reported fires were initiated by vehicle fires and only a small fraction $(\sim 4 \%)$ w as related to spills of gasoline leading to fires or explosions. When vehicle fires are eliminated, the fire frequency is approximately $2.8 \mathrm{E}-2 / \mathrm{yr}$ and when only spills are considered, the average fire frequency is approximately $3 \mathrm{E}-3 / \mathrm{yr}$. The reported fires resulted in, on average, 2 deaths/yr and 70 injuries/yr. Since there were approximately 100,000 public service stations in operation during this period, the average frequency of a fatality or injury associated with the operation of a single gasoline station are approximately $2 \mathrm{E}-5 / \mathrm{yr}$ and $7 \mathrm{E}-4 / \mathrm{yr}$, respectively. If vehicle fires are eliminated, the average fatality and injury frequency associated with operation of an individual gasoline station are approximately 1E$5 / \mathrm{yr}$ and 3.3E-4/yr, respectively. The corresponding fatality and injury frequencies attributable to gasoline spills are approximately 5E-6/yr and 9E-5/yr. How this data is used to establish risk criteria is a critical decision that regulators and other policy makers will have to make if this risk-informed approach is utilized.

\subsection{EXAMPLE APPLICATION OF RISK-INFORMED APPROACH}

To demonstrate he utility of the proposed risk-informed approach, a limited scope QRA was performed for an example hydrogen refueling station with an operating pressure that is not currently reflected by existing codes and standards. Specifically, the analysis was performed for a medium-size hydrogen refueling facility capable of refueling 100 cars/day at a pressure of $70 \mathrm{MPa}$. The scope of 
the analysis presented in this paper is limited to the gas storage area which is one of the focus es of the separation distances specified in most codes and standards.

The facility was assumed to use 51 gas cylinders (250 liters in size) arranged in three cascades for a combined gas storage capacity of $500 \mathrm{~kg}\left(12.63 \mathrm{~m}^{3}\right.$ at $\left.70 \mathrm{MPa}\right)$. The facility design was assumed to meet codes and standard requirements including the presence of saf ety relief valves at important locations that release to elevated vent lines. The facility was also assumed to utilize properly located hydrogen and flame detectors to isolate the discharge pipes from the gas storage area upon detecting either a hydrogen leak or jet flame. However, this isolation capability does not terminate leakage from the gas cylinders and from other components upstream of the isolation valves. Gas flow check valves were assumed present to prevent back flow from one gas cascade to another to limit the duration of a leakage event. Intentional venting of hydrogen to reduce the duration of a detected leakage event was also not included in the current assessment.

Only random component failures leading to hydrogen leakage were included in this example. Leakages initiated by human errors, or natural events, or by other mechanisms such as automobile accidents were not included. Leakage contributions from valves, piping, gas cylinders, connections, and instrument lines were included in the analysis. The assumed size of the piping and valves are representative of a $70 \mathrm{MPa}$ system and vary with location and function. The diameter of the discharge lines from the gas cylinders to the gas inlet and outlet manifolds were assigned a diameter of $6.35 \mathrm{~mm}$ and the manifolds for each cylinder cascade was assumed to have a diameter of $11.5 \mathrm{~mm}$.

Figure 4 illustrates the accident event tree that was used for evaluating the hydrogen release scenarios from the gas storage area The accident sequence modeling is relatively simple since leaks in the gas storage area can not be isolated. The accident event tree includes several phenomenological events that influence the accident sequence and resulting consequences. Included in these phenomenological events are the size of the leak, the potential for immediate ignition, and delayed ignition. The event tree illustrates the resulting consequences for each sequence which includes jet fires, flash fires following delayed ignition of hydrogen (the potential for vapor cloud explosion or hydrogen detonation was not included), and un-ignited gas releases.

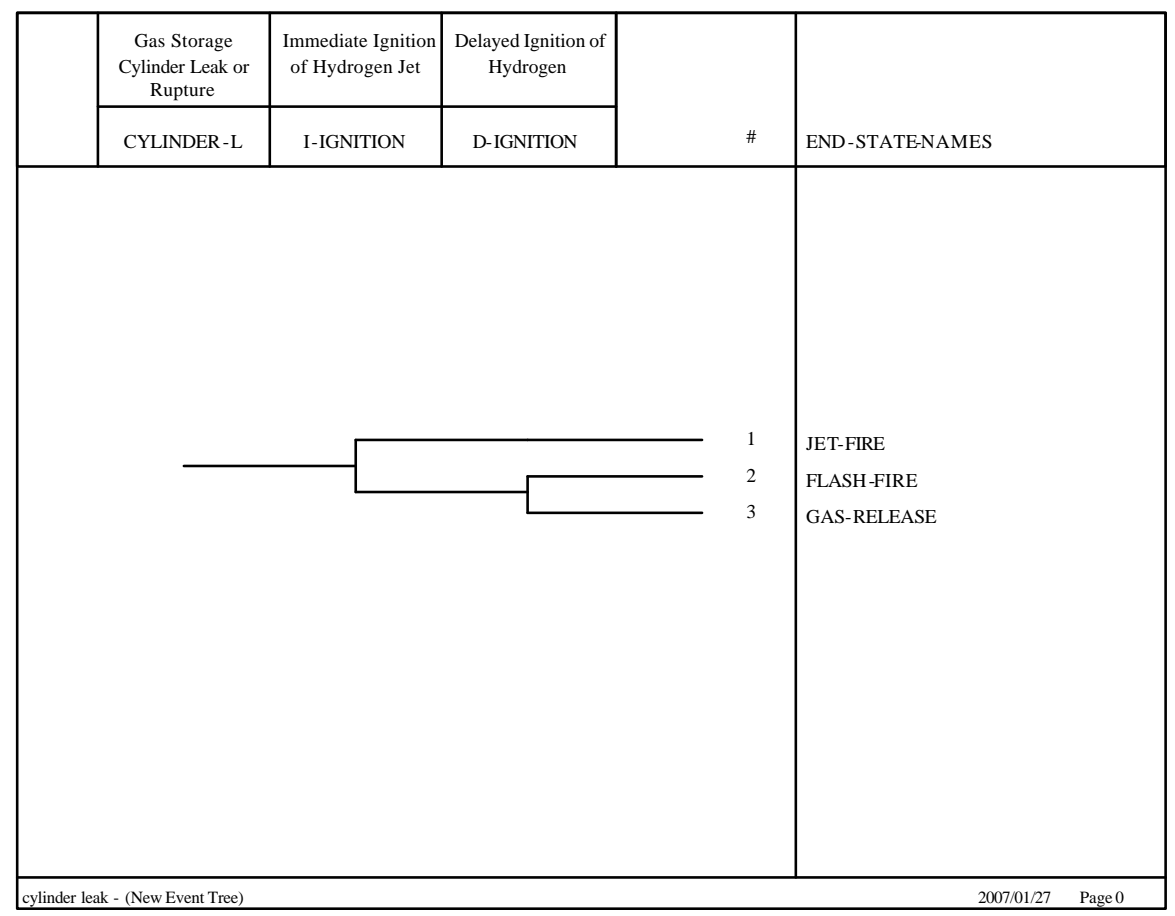

Figure 4. Hydrogen gas storage leakage/rupture event tree. 
Supporting data are required to quantify the event tree shown in Figure 4. The data requ ired includes component leakage frequencies and phenomenological event probabilities (e.g., hydrogen ignition probabilities). Hydrogen-specific data is difficult to obtain and thus data from other sources $[6,15,16,17]$ was reviewed and representative values were selected. The component leakage frequencies utilized in the QRA are shown in Table 1. All of these values were assigned relatively large uncertainty bands to reflect that they do not include hydrogen-specific information.

Table 1. Hydrogen component leakage frequencies.

\begin{tabular}{|l|c|c|c|}
\hline \multirow{2}{*}{ Component } & \multicolumn{3}{|c|}{ Mean Component Leakage Frequency } \\
\cline { 2 - 4 } & Small Leak & Large Leak & Rupture \\
\hline Vessel & $1 \mathrm{E}-4 / \mathrm{yr}$ & $1 \mathrm{E}-5 / \mathrm{yr}$ & $1 \mathrm{E}-6 / \mathrm{yr}$ \\
\hline Pipe & $3 \mathrm{E}-6 / \mathrm{m}-\mathrm{yr}$ & $3 \mathrm{E}-7 / \mathrm{m}-\mathrm{yr}$ & $3 \mathrm{E}-8 / \mathrm{m}-\mathrm{yr}$ \\
\hline Refueling Hose & $0.1 / \mathrm{yr}$ & $1 \mathrm{E}-2 / \mathrm{yr}$ & $1 \mathrm{E}-3 / \mathrm{yr}$ \\
\hline Pump & $3 \mathrm{E}-3 / \mathrm{yr}$ & $3 \mathrm{E}-4 / \mathrm{yr}$ & $3 \mathrm{E}-5 / \mathrm{yr}$ \\
Compressor & $3 \mathrm{E}-2 / \mathrm{yr}$ & $3 \mathrm{E}-3 / \mathrm{yr}$ & $3 \mathrm{E}-4 / \mathrm{yr}$ \\
\hline Electrolyser & $1 \mathrm{E}-4 / \mathrm{yr}$ & $1 \mathrm{E}-5 / \mathrm{yr}$ & $1 \mathrm{E}-6 / \mathrm{yr}$ \\
\hline Vaporizer & $1 \mathrm{E}-3 / \mathrm{yr}$ & $3 \mathrm{E}-4 / \mathrm{yr}$ & $5 \mathrm{E}-5 / \mathrm{yr}$ \\
\hline Valve & $1 \mathrm{E}-3 / \mathrm{yr}$ & $1 \mathrm{E}-4 / \mathrm{yr}$ & $1 \mathrm{E}-5 / \mathrm{yr}$ \\
\hline Pipe Joints and & $3 \mathrm{E}-2 / \mathrm{yr}$ & $4 \mathrm{E}-3 / \mathrm{yr}$ & $5 \mathrm{E}-4 / \mathrm{yr}$ \\
Unions & & & NA \\
\hline Flange & $3 \mathrm{E}-4 / \mathrm{yr}$ & $3 \mathrm{E}-5 / \mathrm{yr}$ & $3 \mathrm{E}-5 / \mathrm{yr}$ \\
\hline Filter & $3 \mathrm{E}-3 / \mathrm{yr}$ & $3 \mathrm{E}-4 / \mathrm{yr}$ & $5 \mathrm{E}-5 / \mathrm{yr}$ \\
\hline Instrument Line & $1 \mathrm{E}-3 / \mathrm{yr}$ & $3 \mathrm{E}-4 / \mathrm{yr}$ & \multicolumn{2}{c}{} \\
\hline
\end{tabular}

As indicated in Table 1, the size of a component leak reflected in available data sources is generally specified in qualitative terms. To utilize the risk-informed approach for establishing safety distances discussed in Section 2, it is necessary to establish the leak frequency for components as a function of leak size. Some guidance in this area is provided by Cox, Lees, and Ang [15] who suggest equating the size of a component rupture to the pipe flow area (A), a large leak to $0.1 \mathrm{~A}$, and a small leak to 0.01A. In addition, a recent review by Spouge [17] of actual leakage data for offshore process pipes indicates that leakage data is an inverse function of the leak diameter (i.e., $f(l e a k>d)=\mathrm{d}^{-\mathrm{m}}$ ). For most offshore components, the Spouge analysis indicates that m ranges from 1.1 to 1.42. Based on both of these inputs, a set of discrete leakage frequencies was generated by treating the leakage frequency as a function of the inverse of the leak diameter (i.e., $\mathrm{m}=1$ ) and anchoring the distribution by equating the component large leak frequency provided in Table 1 to a leak diameter of $1 \mathrm{~mm}$. Thus, small leaks are equivalent to a $0.1 \mathrm{~mm}$ diameter leak and ruptures are assumed to be equivalent to a $10 \mathrm{~mm}$ diameter leak which is approximately the diameter of the manifold pipe assumed in the example analysis. The resulting distributions for components used in this study are shown in Table 2. Note that each frequency represents the frequency of exceeding the specified leakage diameter (i.e., $\mathrm{f}($ leak $>\mathrm{d})$ and that the use of $\mathrm{m}=1$ may be conservative based on the offshore component data.

The phenomenological event probabilities used in this study are shown in Table 3. These values were taken from the available literature and are also highly uncertain. As with the leakage frequencies, the potential for hydrogen detection and ignition were distributed as a function of the leak diameter.

The QRA analysis also required the evaluation of the consequences for each hydrogen release scenario. As indicated previously, the consequences considered in this example QRA were limited to exposure to radiant heat fluxes and flash fires. A Sandia computer model developed by Houf and Scheffer [5] for predicting the behavior of jet flames and hydrogen concentrations was used to determine the resulting consequences for the hydrogen leakage events. The leak orientation was assumed to be directly at the target which results in the longest required separation distances. Examples of the results from this model were presented previously in Figures 1 and 2. 
Table 2. Component leakage frequency-size distributions.

\begin{tabular}{|c|c|c|c|c|c|}
\hline $\begin{array}{c}\text { Diameter } \\
\text { of Leak } \\
(\mathrm{mm})\end{array}$ & $\begin{array}{c}\text { Pipe Leak } \\
\text { Frequencies } \\
(/ \mathrm{m}-\mathrm{yr})\end{array}$ & $\begin{array}{c}\text { Tank Leak } \\
\text { Frequency } \\
(/ \mathrm{yr})\end{array}$ & $\begin{array}{c}\text { Valve Leak } \\
\text { Frequency } \\
(/ \mathrm{yr})\end{array}$ & $\begin{array}{c}\text { Flange } \\
\text { Leak } \\
\text { Frequency } \\
(/ \mathrm{yr})\end{array}$ & $\begin{array}{c}\text { Instrument } \\
\text { Line leak } \\
\text { Frequency } \\
(/ \mathrm{yr})\end{array}$ \\
\hline 0.10 & $3.0 \mathrm{E}-06$ & $1.00 \mathrm{E}-04$ & $1.00 \mathrm{E}-03$ & $3.00 \mathrm{E}-04$ & $3.00 \mathrm{E}-03$ \\
\hline 0.18 & $1.7 \mathrm{E}-06$ & $5.56 \mathrm{E}-05$ & $5.56 \mathrm{E}-04$ & $1.67 \mathrm{E}-04$ & $1.67 \mathrm{E}-03$ \\
\hline 0.40 & $7.5 \mathrm{E}-07$ & $2.50 \mathrm{E}-05$ & $2.50 \mathrm{E}-04$ & $7.50 \mathrm{E}-05$ & $7.50 \mathrm{E}-04$ \\
\hline 1.00 & $3.0 \mathrm{E}-07$ & $1.00 \mathrm{E}-05$ & $1.00 \mathrm{E}-04$ & $3.00 \mathrm{E}-05$ & $3.00 \mathrm{E}-04$ \\
\hline 2.38 & $1.3 \mathrm{E}-07$ & $4.20 \mathrm{E}-06$ & $4.20 \mathrm{E}-05$ & $1.26 \mathrm{E}-05$ & $1.26 \mathrm{E}-04$ \\
\hline 4.23 & $7.1 \mathrm{E}-08$ & $2.36 \mathrm{E}-06$ & $2.36 \mathrm{E}-05$ & $7.09 \mathrm{E}-06$ & $7.09 \mathrm{E}-05$ \\
\hline 6.35 & $4.7 \mathrm{E}-08$ & $1.57 \mathrm{E}-06$ & $1.57 \mathrm{E}-05$ & $4.72 \mathrm{E}-06$ & $4.72 \mathrm{E}-05$ \\
\hline 9.52 & $3.2 \mathrm{E}-08$ & $1.05 \mathrm{E}-06$ & $1.05 \mathrm{E}-05$ & $3.15 \mathrm{E}-06$ & $3.15 \mathrm{E}-05$ \\
\hline 11.50 & $2.6 \mathrm{E}-08$ & $8.70 \mathrm{E}-07$ & $8.70 \mathrm{E}-06$ & $2.61 \mathrm{E}-06$ & $2.61 \mathrm{E}-05$ \\
\hline 13.50 & $2.2 \mathrm{E}-08$ & $7.41 \mathrm{E}-07$ & $7.41 \mathrm{E}-06$ & $2.22 \mathrm{E}-06$ & $2.22 \mathrm{E}-05$ \\
\hline
\end{tabular}

Table 3. Phenomenological event probabilities.

\begin{tabular}{|l|c|c|c|}
\hline \multirow{2}{*}{ Event } & \multicolumn{3}{|c|}{ Mean Probability of Event } \\
& Small leak & Large Leak & Rupture \\
\hline Hydrogen detection probability & 3E-4 & 3E-3 & 3E-2 \\
\hline Immediate hydrogen gas ignition & 8E-3 & $5.3 \mathrm{E}-2$ & 0.23 \\
\hline Delayed hydrogen gas ignition & 4E-3 & 0.27 & 0.12 \\
\hline
\end{tabular}

\subsection{RESULTS OF EXAMPLE ANALYSIS}

The results of the QRA analysis for the gas storage area of the example facility are presented in this section. The results focus on the separation distances required to protect the public from harm. The frequency and consequences for the modeled scenarios are presented in the format required to determine risk-informed separation distances. The results identify which types of scenarios and consequences are most important for determining separation distances for the gas storage area. In addition, the results are used to illustrate how the QRA results combined with different risk criteria could be used to identify separation distances.

The results for the two accident sequences modeled for the gas storage area are presented in Figures 5 and 6. The results for a sequence involving spontaneous ignition leading to a jet fire (i.e., sequence 1 in Figure 4) are shown in Figure 5. Each point on the curves represents the cumulative risk from leaks exceeding a specific diameter and the resulting separation distance that corresponds to the selected consequence parameter for that diameter. For these sequences, the consequence parameters are exposure to radiant heat fluxes or direct flame contact. The separation distances required for three different radiant heat fluxes are illustrated (the distance required for the $25 \mathrm{~kW} / \mathrm{m}^{2}$ heat flux also are representative of the visible flame length and thus provides an indication of where direct flame contact would occur). The risk measures (shown on the yaxis) for these three radiant heat fluxes represent a "no harm" risk $\left(1.6 \mathrm{~kW} / \mathrm{m}^{2}\right)$, the risk of "injury" $\left(4.7 \mathrm{~kW} / \mathrm{m}^{2}\right)$, and the risk of significant "harm" leading potentially to a fatality $\left(25 \mathrm{~kW} / \mathrm{m}^{2}\right)$. The unusual shape of the arve reflects the contribution to risk due to leakage from the different components in the gas storage area.

The results for a delayed ignition leading to a flash fire (i.e., sequence 2 in Figure 4) are illustrated in Figure 6. The delayed ignition is assumed to result in a flash fire out to a distance corresponding to the LFL of $4 \%$ that would result in a risk of significant "harm" possibly leading to death to anyone within the resulting flame distance. The separation distances that would be required for a $2 \%$ 
hydrogen concentration is also shown in the figure to illustrate the distances associated with a "no harm" risk criteria. A comparison of the two figures indicates that both the frequencies and separation distances for flash fire sequences are greater than for the jet fire sequences and thus the consequences from flash fires should determine the required separation distances. The figures also indicate that the risk-informed separation distance can be large for gas storage areas with operating pressures of 70 $\mathrm{MPa}$. Thus, some additional means of mitigating the consequences of leaks is required in order to justify shorter separation distances for this example facility. Sandia is currently evaluating one such mitigation feature - the use of barriers.

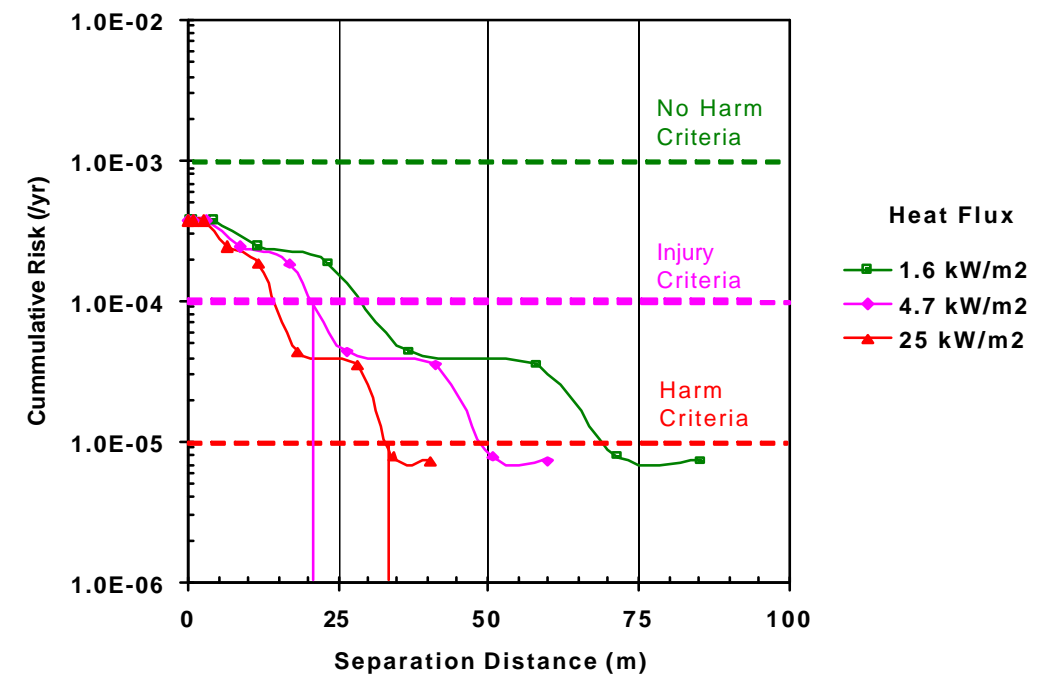

Figure 5. Risk results for unisolated jet fires originating in gas storage area.

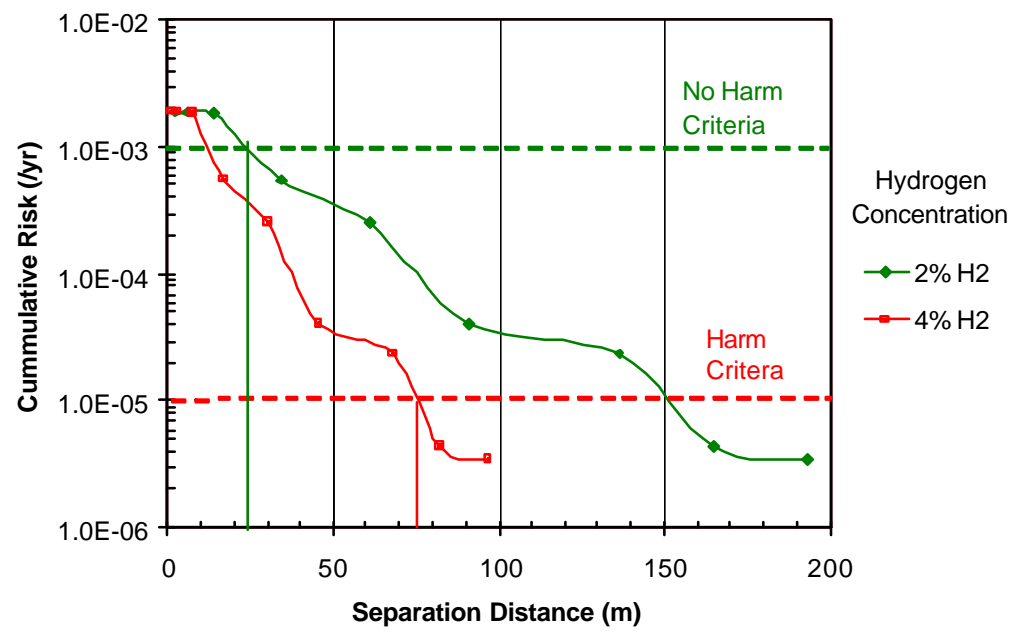

Figure 6. Risk results for unisolated flash fires originating in gas storage area.

The results in Figures 5 and 6 can be used to illustrate the interaction between different risk criteria and consequence parameters on the selected separation distances. Superimposed on both figures are a set of example risk criteria that are consistent with the risk data from gasoline stations presented in Section 2: a criteria of $1 \mathrm{E}-5 / \mathrm{yr}$ for consequences resulting in significant harm to individuals that may lead to death (e.g., flash fire sequences and jet fires resulting in high radiant heat fluxes), a criteria of 
$1 \mathrm{E}-4 / \mathrm{yr}$ for consequences resulting in less serious injuries (e.g., a radiant heat flux level of 4.7 $\mathrm{kW} / \mathrm{m}^{2}$ ), and a criteria of $1 \mathrm{E}-3 / \mathrm{yr}$ for consequences that do not result in harm to an individual (e.g., $2 \%$ hydrogen concentration and $1.6 \mathrm{~kW} / \mathrm{m}^{2}$ ). For the jet fire sequences, the sequence frequencies are below the "no harm" criteria indicating that a short separation distance based on that criteria could be possible. The use of the "injury" and "harm" criteria suggests risk-informed leak sizes that provide separation distances of approximately $20 \mathrm{~m}$ and $35 \mathrm{~m}$, respectively for the example facility. The leak diameters that result in these separation distances are $5 \mathrm{~mm}$ and $10 \mathrm{~mm}$, respectively. The selection of any distance less than those determined by the "harm" criteria would potentially introduce residual risk from larger leaks that would violate the "harm" criteria. Similar results are illustrated for the flash fire scenarios. The "no harm" separation distance is approximately $25 \mathrm{~m}$ for a leak diameter of 2 $\mathrm{mm}$ and the "harm" separation distance is approximately $75 \mathrm{~m}$ for a leak diameter of $10 \mathrm{~mm}$. These results indicate that although it may be desirable to use "no harm" or "injury" consequence measures (e.g., 1.6 or $4.7 \mathrm{~kW} / \mathrm{m}^{2}$ ) to determine separation distances, their use with a relatively high "no harm" and "injury" risk criteria may result in a risk of significant "harm" that violates an accepted "harm" criteria. Thus, it may be required to use a consequence level and a risk criterion that reflects significant injury or death from hydrogen leaks in the risk-informed determination of separation distances.

In the example above, the risk-informed leak diameter, based on a "harm" risk criteria of $1 \mathrm{E}-5 / \mathrm{yr}$, would be $10 \mathrm{~mm}$ and the separation distance $75 \mathrm{~m}$. For comparison, a consequence-based separation distance was calculated using $20 \%$ of the gas cylinder outlet manifold $(\mathrm{d}=11.5 \mathrm{~mm})$ flow area. The equivalent leak diameter is $5.1 \mathrm{~mm}$ and the required separation distance is approximately $37 \mathrm{~m}$ which are less than the risk-informed values. The risk of "harm" for this separation distance taken from Figure 6 is approximately $1 \mathrm{E}-4 / \mathrm{yr}$ which is an order of magnitude greater than the risk criteria. Thus, use of the consequence-based separation distance would result in a level of risk substantially greater than the acceptance criteria.

\subsection{SUMMARY}

A risk-informed approach for selecting the accident scenarios utilized to establish separation distances specified in codes and standards for hydrogen facilities has been proposed. In this approach, the cumulative risk from all accidental releases of hydrogen resulting in one or more specified consequences are evaluated against the separation distances required to protect people, equipment, or structures from a specified level of harm. The estimated risk for the facility is calculated using QRA methods, models, and data, and compared to an acceptable risk level to provide a basis for eliminating low risk scenarios involving large leak diameters from consideration in the determination of separation distances. An additional benefit from the QRA analysis is that key risk drivers are identified and potential accident prevention and mitigation strategies can be identified and possibly specified as requirements in the codes and standards.

An example application of the risk-informed approach has been performed to illustrate its utility and to identify key parameters that can influence the resulting selection of separation distances. Important parameters that were identified include the selected consequence measures and risk criteria, facility operating parameters (e.g., pressure and volume), and the availability of mitigation features (e.g., automatic leak detection and isolation). The results also indicate the sensitivity of the results to key modeling assumptions (e.g., leak orientation and duration) and the component leakage rates used in the QRA models. These insights are being used to generate a set of separation distances for use by SDOs in a risk-informed process to establish or modify hydrogen related codes and standards.

\section{ACKNOWLEDGEMENTS}

This work was supported by the U. S. Department of Energy, Office of Energy Efficiency and Renewable Energy, Hydrogen, Fuel Cells and Infrastructure Technologies Program under the Codes and Standards subprogram element managed by Patrick Davis and Antonio Ruiz. The author would 
also like to acknowledge William Houf who provided the consequence assessments utilized in this analysis.

\section{REFERENCES}

1. “2003 International fire Code,” International Code Council, ISBN \# 892395-60-6.

2. $\quad$ NFPA 55, "Standard for the Storage, Use, and Handling of Compressed Gases, and Cryogenic Fluids in Portable and Stationary Containers, Cylinders, and Tanks," 2005 Edition, National Fire Protection Association.

3. NFPA 52, "Vehicular Fuel Systems Code", 2006 Edition, National Fire Protections Association.

4. 29 CFR Occupational Safety and Health Administration, $\mathbb{2 1 9 2 0 . 1 0 3 ~ H y d r o g e n . ~}$

5. W.G. Houf and R.W. Schefer, "Predicting Radiative Heat Fluxes and Flammability Envelopes from Unintended Releases of Hydrogen," International Journal of Hydrogen Energy, Vol. 32, pp. 136-151, January 2007.

6. "Determination of Safety Distances," European Industrial Gases Association, IGC Doc 75/07/E, 2007.

7. $\quad$ F.P Lees, "Loss Prevention in the Process Industries," Third Addition, Elsevier Butterworth-Heineman, Burlington, MA, 2005.

8. Thomas F. Barry, "Fire Exposure Profile Modeling: some Threshold Damage (TDL) Data," www.fireriskforum.com.

9. Phani K. Raj, "Hazardous Heat,” NFPA Journal, September/October 2006.

10. "Standard for the Productions, Storage, and Handling of Liquefied Natural Gas (LNG), National fire Protection Association, NFPA 59A, 2006.

11. "Risk Management Plan Guidance Document for Bulk Liquid Hydrogen Systems," CGA P28, Compressed Gas Association, Second Edition, 2003.

12. "Injury Facts," 2007 Edition, National Safety Council

13. "Risk Acceptance Criteria for Hydrogen Refueling Stations," European Integrated Hydrogen Project, February 2003.

14. "Fires in or at Service Stations and Motor Vehicle Repair and Paint Shops," National Fire Protection Association, April 2002.

15. A.W. Cox, F.P. Lees, and M.L. Ang, "Classification of Hazardous Locations," Institution of Chemical Engineers, May 2003.

16. C.H. Blanton and S.A. Eide, "Savannah River Site Generic Data Base Development," WSRC-TR-93-262, Westinghouse Savannah River Company, June 30, 1993.

17. John Spouge, "New Generic Leak Frequencies for Process Equipment," Process Safety Progress (Vol. 24, No. 4), December 2005. 